\section{La literatura y su enseñanza... Segundo llamado}

\author{
Literature and Its Teaching... \\ a Second Call
}

\author{
Literatura e ensino... \\ Segunda chamada
}

\section{Guillermo Bustamante Zamudio*}

* Doctor en Educación Universidad Pedagógica Nacional de Colombia y Magister en Lingüística y español Universidad del Valle. Profesor Titular Universidad Pedagógica Nacional. e-mail: guibuza@gmail.com

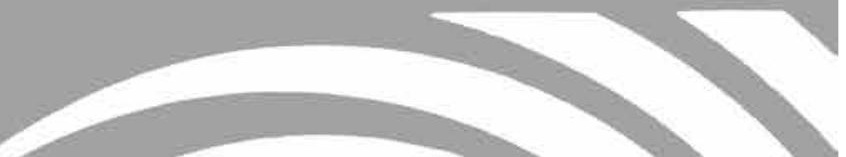

\section{Resumen}

Como todo asunto social, la educación es objeto de explicaciones; sin embargo no todas tienen el mismo nivel de elaboración, y la vía política suele imponer alguna temporalmente, lo cual no le da legitimidad conceptual. Dada la condición humana, lo regulativo es constitutivo, no algo impuesto a la inerme educación, y eliminable a nombre de sus frecuentes excesos. Así, la enseñanza de la literatura no puede evadir su dimensión regulativa, aunque se crea que su asunto está ligado a una libertad incondicional, mientras su producción y su consumo requieren restricciones. El acceso a la literatura no es libre y espontáneo; crearle condiciones de posibilidad no siempre va en el sentido de lo que los estudiantes quieren "naturalmente". En esto, la asignatura no es diferente de otras y su dimensión instruccional está en relación con la especificidad de la escuela.

\section{Palabras clave}

Regulación, instrucción, libertad, efectos, sometimiento consentido

\section{Abstract}

Like any social issue, education is subject to explanations. However, not all of them have the same level of development, and the political way usually imposes one temporarily, which deprives it of any conceptual legitimacy. Given the human condition, the regulative is a constituent element of education, not something imposed to education, and deletable on behalf of its frequent excesses. Thus, the teaching of literature cannot evade its regulatory dimension, even though some believe it is an issue of unconditional freedom, while its production and consumption require restrictions. Access to literature is not free and spontaneous. Creating conditions of possibility does not always meet what students want "naturally". In this sense, this subject is not different from others, and its instructional dimension is related to the specificity of the school.

\section{Key words}

Regulation, instruction, freedom, effects, consensual submission

\section{Resumo}

Como qualquer tema social, a educação é objeto de explicações; no entanto, nem todos têm o mesmo nível de desenvolvimento e a rota política geralmente impõe alguma temporariamente, o que não lhe dá legitimidade conceitual. Dada a condição humana, o regulador é constitutivo, não é algo imposto para a educação e também não é eliminável em nome de seus excessos frequentes. Assim, o ensino da literatura não pode evitar sua dimensão reguladora, ainda que se acredite que sua natureza está ligada a uma liberdade incondicional, enquanto sua produção e consumo requerem restrições. 0 acesso à literatura não é livre e espontâneo; é preciso criar para ele condições de possibilidade que nem sempre vão na direção do que os alunos querem "naturalmente". Neste ponto, a disciplina escolar não é diferente de outras disciplinas e sua dimensão instrucional está relacionada com a especificidade da escola.

\section{Palavras chave}

Regulação, instrução, liberdade, efeitos, submissão consensual

Fecha de recepción: Septiembre 20 de 2015 Fecha de aprobación: Noviembre 26 de 2015

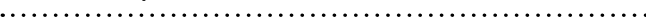




\section{¿Una rejilla posible?}

E n 2013, ofrecí una Lección Inaugural en la Maestría en Educación de la Universidad Pedagógica Nacional con el título "El maestro cuadrifronte". Ese texto -inédito- prosigue una parte de mi tesis doctoral Sujeto, sentido y formación (2013). El planteamiento central de la lectio era que el maestro tiene cuatro rostros, correspondientes a cuatro asuntos muy distintos y, hasta cierto punto, excluyentes. Así, formar un licenciado no sería un asunto lineal, en el que se sumen aspectos integrados en las asignaturas; ni la labor del maestro sería aplicar saberes y métodos aprendidos durante la carrera, o aplicar un "saber pedagógico" que crece paulatinamente en la práctica (nueva versión de la antigua "experiencia", sin el incómodo asunto de los vicios). Decía también que, tarde o temprano, esta propiedad múltiple del oficio nos pasa cuenta de cobro: maestros jubilados antes de tiempo por asuntos de salud, primer gremio en frecuencia de consulta de salud mental, sensación de no haber sido compensados en toda la dimensión de su labor...1

Por supuesto, respondemos de manera desigual a esos cuatro desafíos. A veces, a la luz de estereotipos de moda, pretendemos deshacernos de alguno, creyendo hacerle un favor al proceso educativo; pero en realidad - sin saberlo-, o bien ponemos otra cosa en su lugar, o bien permitimos que algo venga a ocuparlo.

Entonces, un sistema de cuatro elementos, cada uno con una escala de posibilidades entre 'sí' y 'no', y con la opción de poner o no algo en el lugar despejado, o que algo venga o no a ese lugar... produce ya una inmensa combinatoria. Creo que, con ayuda de esa matriz podría caracterizarse, en alguna medida, la diversidad de los maestros. Hay que trabajarle más. Acá intentaré usar ese recurso en la comprensión -apenas aproximativa- de algunos aspectos ligados a la enseñanza de la literatura. Es un trabajo en desarrollo.

\section{¿Descripción legítima de la educación?}

La educación, como todo asunto social, ha intentado ser descrita por muchos discursos; entre estos, no "le corresponde" uno en particular, como si ella fuera su objeto exclusivo (ese tipo de reclamo, próximo a lo jurídico, no solo renuncia a la comprensión, sino

1 Ver datos al respecto, en el caso de Brasil, en el siguiente vínculo: http://observatoriopedagogicodemedios.blogspot.com.co/search/label/Econom\%C3\%ADa\%20y\%20 universidad\%20en\%20Brasil que también resulta ineficaz de cara a su propia intención). Ahora bien, esto no busca dar entrada a la monserga "interdisciplinar"; más bien busca señalar que la educación es una arena donde pugnan fuerzas (Bourdieu, 2000, p. 64).

Constatamos, entonces, que diversos discursos han querido dar cuenta de lo que allí pasa. En una época, se hacía referencia a algo de esa pluralidad con la equívoca expresión "Ciencias de la educación", hoy casi en desuso. También constatamos que, históricamente, unos discursos han tenido más fuerza que otros para imponerse; entiéndase bien: imponer su descripción como legítima, lo que hace que muchos de los involucrados en el asunto educativo empiecen a utilizarla como tal (con fe, con resignación o con sospecha, es lo de menos en este nivel de análisis).

Con todo, lograr ese puesto nada dice en relación con la justeza de las explicaciones o con la prioridad que unos discursos deberían tener en relación con otros (como creen, por ejemplo, quienes abogan por el "estatuto epistemológico de la pedagogía"). Esto sólo evidencia que un discurso se ha impuesto, al menos por un tiempo, en un campo donde varios siguen intentándolo. Así, por ejemplo, afirmar que hoy los discursos de la administración y de la psicometría tienen el control simbólico frente a la interpretación de lo que pasa en la escuela, que sus afirmaciones son la base de las decisiones y el foco de las controversias... es solamente describir el estado de la pugna; quiere decir que los otros discursos (incluyendo los que se reputan "más específicos", o "más justos", o "más actuales", o "más pertinentes", etc.), van perdiendo en una pugna que no solo consiste -insisto- en argumentos, sino que aplica "todas las formas de lucha", pues lo que está en juego son intereses económico-políticos (y, en ese marco, agendas personales). No quiere decir que se ha traicionado la especificidad de la escuela, pues el sentido de tal especificidad es justamente una parte de lo que motiva el antagonismo: cada uno cree tenerlo en el bolsillo... el problema es que los otros también; tampoco quiere decir forzosamente que ahora la escuela es otra cosa y que, en consecuencia, nos "toque" pensarla con arreglo a esos discursos (como dicen los resignados, sin dejar de atender su negocio).

De esta forma, la imagen resultante es la de una o varias especificidades, describibles de varias formas, apropiables por un sinnúmero de intereses, de maneras también diversas. Múltiples intereses, no implica igual nivel de legitimidad; y múltiples descripciones, no supone el mismo grado de rigor. En la escena no cabe la idea de desarrollo ("progreso", "mejoramiento") o de democracia ("igualdad", 
"participación"), o de eficacia, de manera que las descripciones de hoy se puedan considerar mejores o más justas que las de ayer, o que los intereses de hoy tengan más legitimidad que los anteriores. Incluso las descripciones van y vuelven. A veces recargadas, a veces descargadas ${ }^{2}$. Es el lugar donde la política verifica sus posibilidades y alcances, no el lugar donde las teorías encuentran su "prueba", pues solo una pobre epistemología cree que la realidad, a secas, es una fuerza probatoria (Bachelard, 1949).

Ingenua manera de tapar este sol con las manos es declarar a la pedagogía como ciencia. Como si todos los que aspiran a entender la educación fueran a retroceder de inmediato ante esta declaratoria, al ser llamados al orden: "ocúpense de lo suyo que esto ya tiene dueño". Mal favor al saber ese de andar declarando ciencia - o, peor, "interdisciplina" - a cada feudo que queremos conquistar, a cada pensamiento que queremos proteger, a cada tema que nos resulta interesante, a cada subdivisión que creemos justificada ${ }^{3}$.

Con este punto se sembraría ya un mojón en relación con la enseñanza de la literatura: la manera correcta de entenderla y el sentido justo de su enseñanza no serían más que un estado de la pugna. Ahora bien, eso no iguala todas las prácticas pedagógicas a su nombre, pues ellas hacen referencia a un asunto estructural, pero este - justamente por su naturaleza- abre el abanico y es susceptible de múltiple interpretación. Lleva la humanidad unos cuantos milenios discutiendo qué es lo estético, qué lugar tiene eso que modernamente llamamos "arte"... de manera que ingenuo sería pensar que una propuesta formativa en el área de la literatura responde cabalmente esas preguntas. Además, se trata de la literatura en el marco educativo, donde tales preguntas experimentan transformaciones y donde se van a agregar otras, específicas de ese ámbito.

\section{¿Tiene lugar lo regulativo?}

Para Bernstein (1993), el dispositivo pedagógico consta de dos dimensiones: regulativa e instruccional. Este planteamiento, elemental, ya constituye una

2 El discurso sobre la inteligencia se impuso en la escuela durante un tiempo. Años después, el discurso sobre las competencias también trata de imponerse como algo diferente. Pero, estructuralmente hablando, son casi idénticos... y, en cada caso dicen traer "lo último", lo que "ahora sí", va a acabar con todos los problemas.

3 Ciencia sería la biología (vida), y también la zoología (animales), y también la craniatología (vertebrados), y también la mastozoología (mamíferos), y también la primatología (primates) y, por qué no, la orangutanología (orangutanes)... división de aguas: en el campo educativo, ciertas voces se quejan de la regulación, la denuncian como poder opresivo, represor, castrante, etc. Un ejemplo en la enseñanza de la literatura: el "control de lectura" diluiría el goce estético, así como el análisis de las obras mataría la literatura. También escuchamos explicaciones según las cuales habría un discurso "ajeno" a la educación que nos han metido a la fuerza, responsable, por ejemplo, de ciertas prácticas evaluativas, venidas - dice la cantilena- de no sé qué discurso empresarial (para citar uno de los últimos advenedizos); de donde la regulación sería externa a la educación. Así, cuando uno intenta ver si los estudiantes leyeron la novela asignada, se convierte en un agente del capitalismo salvaje.

Acá decimos algo distinto: lo regulativo es constitutivo de la escuela. No es algo "ajeno" que le imponen a la inerme educación. De tal forma, se abriría la posibilidad de entender ( $i$ no es eso lo que buscan los investigadores?) por qué un discurso que viene - digamos así, en gracia de discusión - de la administración de empresas, entra a la educación como a su propia casa, y se queda viviendo ahí. Y, de manera particular, sería posible entender por qué quienes consideran perjudicial el control de lectura o el análisis literario, para seguir con el ejemplo, pretenden realizar prácticas que, si bien difieren de otras, también podrían motejarse de la misma manera. Estar en desacuerdo y tener la crítica lista (plastificada) antes de que haga aparición el presunto enemigo no explica por qué existen esas prácticas. Si solo podemos decir algo sobre la educación con un lenguaje de dramatizado (de "auténticos" y "espurios" o, si se quiere, con una jerga que denuncia el poder en términos de "víctimas" y "victimarios"), pues se trata del legítimo terreno de la política - si es asumido pobremente o no, es otra discusión-, y no del terreno de la investigación que decimos hacer en el campo educativo (referida al saber).

Ahora bien, esto no justifica cualquier práctica regulativa; simplemente sostiene que la regulación es constitutiva. Y hay prácticas regulativas "autoritarias", o sea, que exceden el monto necesario de regulación, por decirlo así, y no estamos de acuerdo con ellas... pero justamente eso es un reto para la investigación: ¿por qué se produce ese exceso?, ¿cómo está hecha la escuela para que eso pueda darse?; o, en términos de la propuesta del maestro cuadrifronte: dada esa manera particular de aparecer la regulación, ¿cómo se articulan los diversos elementos? Y, desde esta perspectiva, es igualmente motivo de investigación el discurso que pretende sustraerse de la función regulativa, pues aunque parezca "políticamente 
correcto" no deja de producir efectos comparables a los que produce su opuesto; y con esos efectos —valga aclararlo-, tampoco estamos de acuerdo.

Denunciar el autoritarismo y no el "blandismo" revela una postura que tal vez no está interesada en comprender, pues no se aplica a sí misma lo que aplica a lo demás, siendo que tenemos investigación científica en el campo social cuando esta aplica al investigador mismo, a su campo, a su grupo, a su sociedad (Lévy-Strauss, 1960, p. 35). La denuncia política puede usarse como sustituto fácil de la crítica científica (Bourdieu, 1982, p. 28).

En el marco de una disciplina, los asuntos por investigar no provienen de los propósitos, buenos o malos, sino de la confluencia de múltiples determinaciones, como decía Marx (1859). Si solo fuera un asunto de buena voluntad (en cualquier ubicación del espectro político), no se necesitaría investigar, y bastaría con encuestar a los protagonistas sobre lo que se proponen... cosa que efectivamente hace cierto tipo de práctica que, en el ámbito educativo, se denomina "investigación educativa" (curioso bautizo: por el objeto al que aplica, no por el campo del que procede o por la especificidad de su acción).

\section{¿Por qué dimensión regulativa?}

Aquellos a quienes nos proponemos instruir no parecen estar dispuestos a "ser instruidos". El hecho de proponernos instruirlos muestra que no quieren instruirse o, en su defecto, que no quieren ser instruidos. Todo el que enseña sabe que lucha contra una resistencia. La instrucción que les interesa espontáneamente a los nuevos sería la que conduzca a - o, al menos, que no altere- su satisfacción más inmediata y autista; el futuro de la cultura tendría contados los días si nos mostraramos sumisos frente a tal condición.

En principio, entonces, la escuela es una imposición. ¿Quiere decir eso que se trata de algo negativo? Es que algunos, cuando oyen palabras como imposición, autoridad, norma o regulación sacan el revólver ${ }^{4}$, tal como decían que el cercano al Reich (el mariscal Göring o el ministro Goebbels) sacaba la pistola al oír la palabra cultura. Pero, en ese mismo vecindario, unos años antes, Kant (1803) enseñó

4 No obstante, cuando juegan, se imponen - e imponen a sus contrincantes - unas reglas que no están en discusión; y se molestan cuando esas reglas no se cumplen o alguien intenta transgredirlas.

5 Sus cursos de pedagogía quedaron reseñados en el opúsculo Pedagogía, que lleva su autoría - y tiene su autorización-, aunque lo hizo un estudiante, a partir de las notas de clase. que, a diferencia de los otros animales, la desprogramación del humano recién llegado hace que sus semejantes se apresuren a trazarle un plan. Así, no hay manera de que no haya imposición de la cultura. Esto no implica la validez de cualquier contenido del plan (incluso podríamos preguntarnos si alguno lo ha sido), sino solamente que dicho plan es necesario, en el sentido de la lógica modal: no puede no estar. Es necesario transmitir la cultura - usando una cultura- al recién llegado; pero como no la quiere, no se trata entonces de darle a quien necesita, sino de hacer que el otro consienta esa imposición (esta idea - de cuño psicoanalítico- no es contradictoria, solo intenta recoger la complejidad del asunto). Evoquemos nuevamente el juego: las ganas de jugar hacen que consintamos en someternos a sus restricciones. Y, con mayor razón, la literatura: se trata de un contrato en el que aceptamos, por un lapso de tiempo, ser engañados, siempre y cuando el otro lo haga de manera verosímil.

El saber, que puede ser una fiesta para quien ya se regocija en él, no es más que una imposición aburrida para quien no lo conoce. Y, paradójicamente, no podría llegar a regocijarse con él, si el otro no se lo presenta formalmente, supuesta función de la escuela. Así, la dimensión regulativa busca conseguir las condiciones de posibilidad para el saber, pues no están dadas de manera espontánea. Por supuesto, hay "métodos" que hacen más dramática la cuestión, pero el asunto no es simplemente de "falta de pedagogía", ni de "falta de didáctica", sino de un obstáculo estructural de entrada.

Y si, para oponernos a la norma, postulamos un desarrollo espontáneo, sin la presencia del otro (con sus odiosas normas, exigencias y tareas), somos todavía más autoritarios que aquello que estamos intentando neutralizar, pues estaríamos dejando el puesto de la tiranía al impulso - para usar el término de Kant- que conduce a una impotencia exclusiva de los humanos: aquella que consiste en no poder... parar. Y si alguien no puede parar, si espera la satisfacción ya, si no puede aplazar, ¿cómo hacemos para que lea Los hermanos Karamasov? No en vano, para Kant la disciplina consistía en quitar, mientras la instrucción consistía en dar. Es claro: solo se puede dar si existe ese espacio dejado por el quitar; si no se ha quitado, no hay dónde alojar un saber. ¿Está Sócrates cercano a esta perspectiva, haciéndole un espacio a la posibilidad?, ¿no es una manera interesante de pensar la formación?

Entonces, la dimensión regulativa busca dar lugar a la instruccional, pues las condiciones para esta no están provistas a priori, ¡hay que construirlas! 
¡Eso es parte de la labor del docente! Educar no es como dar de beber a un sediento (enseñaba Platón y recordaba Zuleta): ¿cuál sería la labor del docente si ya los estudiantes quisieran aprender?

El maestro, entonces, tiene funciones a escala de la regulación, sencillamente porque, para las personas que le han sido encomendadas, el saber no es asunto en relación con el cual construyan horizonte... pero puede llegar a serlo. Las energías se emplean más bien de una manera múltiple, nombrada por los maestros mediante expresiones como "inquietud" o "indisciplina". No por otra razón la escuela se ve obligada a otorgar recreos, jreconociendo que en la clase los estudiantes no se recrean!; o a proporcionar "bienestar universitario", jcomo si en la clase se dispensara malestar! Además, las energías se emplean de mala gana en relación con el saber: pereza de leer, tareas realizadas por obligación, distracción, indiferencia ("les entra por un oído y les sale por el otro"). Nada de esto es "falta de voluntad", pues el sueño se disipa como por arte de magia cuando una señal indica el fin de la clase, y vemos mucha voluntad en el patio, en los baños, en la cafetería y en los alrededores de la institución educativa. Si algo falta en este panorama, no es voluntad.

Pues bien, esa es la condición dada y, por eso, la dimensión regulativa es indefectible. Cuando las personas tienen el saber como un asunto importante en relación con el cual orientar su existencia, pues no son alumnos, sino pares, y ya no operaría con ellos la relación que hace posible llamar la atención, calificar, mandar un memo, intervenir la hoja de vida, suspender o expulsar.

Entonces, parte de la tarea de formar es crear las condiciones (dimensión regulativa) para poner en escena el saber (dimensión instruccional). Así, el maestro es un funcionario; esa es su primera cara: está bajo contrato, le pagan para que trabaje; y tiene funciones regulativas muy claras: llama a lista, cuida el orden, reprende, califica; a veces le corresponde el turno de "vigilar" durante el recreo; tiene tareas administrativas: entrega notas a la autoridad competente, reenvía estudiantes a distintas dependencias de la institución; puede ocupar un lugar en la dirección de un departamento o en el consejo académico; ocasionalmente, organiza una actividad especial (a los de literatura nos corresponden el Día del Idioma, los "centros literarios", los concursos); atiende padres de familia; responde a requerimientos institucionales; quizá esté afiliado al sindicato, lo cual solo es posible por ser una persona contratada por el Estado para ejercer una labor.
Con todo, los asuntos de la dimensión regulativa no siempre están relacionados con consignas explícitas o actos conscientes. Un tono en el hablar, un cambio en las maneras de hacer en clase... pueden indicar a los estudiantes que su comportamiento tal vez no está facilitando las cosas, o que se hace necesario cambiar de actividad; aprobar o desaprobar una tarea es una manera de enjuiciar las prácticas que la hicieron posible, y regula tácitamente las que vienen. Esta forma poco visible de lo regulativo no es menos importante. Acaso podríamos decir que las prácticas regulativas más visibles expresen, a escala institucional, esta sutil manera de tratar de hacer que el otro trabaje. La necedad de cierta oposición incondicional a la regulación se expresa en el hecho de atacar sus formas más visibles, sin saber que uno mismo practica las menos visibles.

Si bien hay quien gusta de la administración, y maestros con posgrados de "gerencia educativa", y personas que prefieren ser rector que profesor, los asuntos regulativos no dependen del gusto o de la elección: si no se los lleva a cabo, se falta a una obligación y se puede ser objeto de proceso disciplinario, de sanción. Claro que se puede "hacer como si", escabullirse sin dejar de responder a esa dimensión de funcionario (son algunas de las capacidades desarrolladas durante la práctica). Puede que nuestro espíritu libertario crea que se contamina si llena un formato o si le llama la atención a un estudiante. Sin embargo, si nadie llenara formatos, si nadie llevara un registro de lo que pasa, si no hubiera un reglamento contra el cual comparar una acción para tomar decisiones, si no hubiera una señal que indica el comienzo o el fin de la labor, si no hubiera sanciones aprobatorias o desaprobatorias... la escuela no sería posible.

El discurso regulativo tiene que ver con la escuela, porque ella también es regulativa; es decir que siempre lo es: no podría dejar de serlo, así nos portemos de la manera más igualitaria posible. En consecuencia, eliminar la regulación tal vez produzca otro tipo de dispositivo, pero no una "escuela sin regulación".

\section{¿Una regulación ecuánime?}

No toda acción de orden regulativo es justificable: es evidente que hay excesos y defectos al respecto. No obstante, la existencia de prácticas regulativas injustificadas no quiere decir que la regulación per se lo sea. Junto con el agua sucia, solemos botar al bebé.

En ciertos momentos y en ciertos casos, vemos que la dimensión regulativa gana independencia y parece como si lo académico le estuviera subordinado; como si la instrucción fuera una realización 
de la regulación, como si solo dependiera de un mandato. Son momentos de la pugna ya descrita. Sin embargo, el "avance" del discurso administrativo (la inversión de la relación regulación/instrucción), ¿es achacable únicamente - como escuchamos decir-a cierta incomprensión, a dudosos intereses políticos, a la mala voluntad de algunos, a sesgados discursos subliminales? Eso sería olvidar una variable: en alguna medida, esa inversión también depende de la postura asumida frente a la dimensión instruccional; como cuando se hace dejación del saber (o sea: renuncia a la instrucción), según se verifica hoy. De hecho, hoy se injuria con el adjetivo "academicista", se denigra de lo "magistral" (habría que cambiarlo por lo "participativo"), se desprecia la tradición (el adjetivo "tradicionalista" es peyorativo, pues lo que habría que hacer es innovar), etc. Así, paso a paso, en las clases de literatura va desapareciendo Homero para que aparezca Coelho; se nombra cada vez menos a Cervantes y para todos se va volviendo más reconocible Walter Riso.

Y, claro: ¿ dónde más se iba a instalar la exacerbación del papel de los formatos y de la planeación, sino allí donde quedan espacios sin ocupar? Vemos cambios en la educación colombiana que tienen que ver con un "no sabemos", incluso con un "no queremos saber". Por ejemplo, lo relacionado con la autonomía. La ley 115 la "otorgó" a los PEI y estableció lineamientos generales de procesos curriculares (MEN, 1994), según los cuales las instituciones y los profesionales de la educación podían hacer sus planes de estudio... Sin embargo, dijimos no estar capacitados, corrimos a buscar viejos currículos, tomados en marcos de relación supuestamente distintos; terminamos exigiendo lo mismo de siempre. Ante ese paso atrás, la contraparte da un paso adelante, no es de extrañar: indicadores de logro, lineamientos curriculares y, finalmente, estándares (MEN, 2006). Todo lo contrario de lo que se había decretado al comienzo, resultado - entre otros- de esa declaración de no querer saber. Por supuesto, no es un asunto monocausal: medidas como esas tienen varias razones para existir, pero nuestro retroceso no solo es una de ellas, sino también condición para que otras causas - vengan de donde vengan- logren operar.

Con todo, la expresión de lo regulativo como dominante no está solamente en un discurso administrativo oficial que asfixia a la academia, sino también, y de manera menos visible, en el trueque que se puede hacer en clase: cambiar saber por discurso sobre los valores. En lugar de enseñar literatura, ¿no valdría más bien llegar de una vez al propósito de tal enseñanza y promover la igualdad entre los miembros de la comunidad educativa?

\section{¿Escapar a lo regulativo?}

Hay profesores de literatura dispuestos a conceder la existencia de la regulación en ciertos ambientes escolares, en otras asignaturas, mas no en la suya: ¿no es acaso el arte el reino de la libertad? De ahí que, en un artículo titulado "La imaginación literaria en la vida pública", Martha Nussbaum afirme:

La literatura y la imaginación literaria pueden tener un efecto subversivo frente a la idea de racionalidad expresada habitualmente por la ciencia económica utilitarista. Por ello, la literatura debe formar parte de una educación en favor de una idea de racionalidad pública más amplia que la idea de individuo como maximizador de utilidades. (1991, p. 42)

Pero, en primer lugar, ¿por qué tendrían que oponerse la imaginación literaria y la racionalidad? Una literatura sin racionalidad sería incomprensible. La mejor manera de subvertir un discurso económico utilitarista, ¿no sería la producción de un discurso económico racional? Ahora bien, al hablar de "ciencia económica utilitarista”, uno debería oponerse a la racionalidad económica, pues está calificada de "utilitarista". Pero, en realidad, la introducción del utilitarismo con tanta fuerza tal vez hable más bien de una modalidad discursiva donde hay un uso de la economía al servicio de eso que Nussbaum rechaza (que, entonces, ya no sería "ciencia económica"). La ciencia, en principio, no es utilitarista, aunque efectivamente se intente utilizarla en direcciones muy distintas. ¡No podemos decir que Marx, por hacer ciencia económica, estaba pensando en un individuo como "maximizador de utilidades"! ¿No es todo lo contrario? Estas afirmaciones de Nussbaum ejemplifican muy bien una modalidad discursiva consistente en no argumentar y pedir adhesiones, pues lo que exhibe son consignas. Consignas que no aportan a la comprensión de la literatura y de su enseñanza (tema de la cita). Por eso concluye falazmente: "la literatura debe formar parte de una educación en favor de una idea de racionalidad pública más amplia que la idea de individuo como maximizador de utilidades". De un lado, por el hecho de introducir el "deber", se aparta de un intento de comprensión, pues pasa a prescribir. Y la educación, si bien tiene adosados unos cuantos deberes, funciona más bien como matriz de posibilidades, dada la articulación específica que ganan ciertos elementos (tales como los sujetos y los saberes). De otro lado, ¿qué estatuto para una "racionalidad pública"?, ¿se trata acaso del sentido común?; por no ser pública, ¿la ciencia económica es inferior? 
Continúa Nussbaum (1991, p. 42): “... sólo la imaginación proporcionada por las novelas -y no por los libros de economía política- puede ser la base para gobernar adecuadamente un país de personas libres e iguales o para desarrollar nuestra vida cotidiana como ciudadanos". La ciencia política no puede proponerse semejante meta, pues ella - como explica Weber [1904] - solo podría señalar la relación de los propósitos políticos con las condiciones de posibilidad descritas científicamente. Pero ahora resulta que la especificidad de la literatura es saber sobre el gobierno de personas libres e iguales. Por supuesto que la literatura algo sabe sobre las personas, pero saber no es su asunto constitutivo. Así como hay un uso abusivo de la ciencia económica por parte de quien la convierte en una justificación del sujeto como maximizador de utilidades, así también Nussbaum abusa de la literatura para hacerla hablar de algo que ella no es.

¿De qué libertad hablamos? Hoy esa palabra en la escuela suele esgrimirse en detrimento de la exigencia y de la disciplina (y, sin embargo, "Las obras no son producto de hombres libres" [Quignard, 1996, p. 10]). Pero la libertad también podría ser todo lo contrario: un efecto posible de la relación con el saber; es decir, no se daría en ausencia del saber y de la disciplina.

Además, la idea según la cual la libertad se juega en relación con asignaturas como la literatura, pero no con otras como las matemáticas, es un doble error: de un lado, no se entiende el propio campo (¿cómo produce libertad la literatura?) y, de otro, se descalifica ingenuamente a los otros, pues - por el contrario-se puede afirmar que todo conocimiento ejerce un efecto liberador (Bourdieu, 1982, p. 22). Si algo de libertad se materializa en la escuela, no será por el contenido de las asignaturas o de las arengas. $\mathrm{Si}$ así fuera, los currículos - liberadores u opresivosse habrían determinado conforme a ese parámetro. ¿Será así de fácil?: ¿nos quieren dar libertad y, por eso, se imparte la clase de literatura; $y$, al mismo tiempo, nos la quieren quitar y, por eso, se imparte la clase de matemáticas? Los buenos propósitos de transformación de la escuela (como el de inocular libertad en la asignatura de literatura), tal vez formen parte de la "ambición mágica de transformar el mundo social sin conocer sus mecanismos", como dice Bourdieu (1982, pp. 36-37), que "se expone a sustituir por otra violencia, a veces más inhumana, la 'violencia inerte' de los mecanismos".

Y cuando pensamos que el secreto no está en el contenido, sino en la metodología, entonces pintamos todo con la palabra 'lúdica', en atención a que
- supuestamente- en el juego habría libertad. Y se usa la literatura en ese sentido cuando, en otras asignaturas, se le extraen partes (la historia de Colombia que habría en Cien años de soledad, la geografía del mediterráneo que habría en Odisea, etc.), o se la pone al cierre para finalizar lúdicamente las actividades: con una composición, un cuento, una representación teatral. Sin embargo, paradójicamente, el juego es - por excelencia- el espacio de la regulación: no se puede jugar sin reglas. Es más: solo se puede hacer trampa (pasión de los chicos) si hay reglas que transgredir.

Entonces, un prurito "libertario" y "anti-antiautoritario" campea en las toldas literarias. No obstante, sería ingenuo pensar que las formas de representarse las cosas, para tener un lugar en ellas, coinciden con su especificidad. Al arte no le atañe la libertad... $\mathrm{y}$, de una vez, para atajar las supuestas objeciones que saltan ante una idea como esta, digamos: al arte tampoco le atañe el sometimiento. ¡Está en un registro distinto al de esa oposición! Y como, además, nuestro tema es la enseñanza (de la literatura), digamos: la libertad no es asunto de enseñanza alguna, aunque puede tener que ver con sus efectos. En las Nuevas conferencias de introducción al psicoanálisis, dice Freud (1932, pp. 139-140) que la labor pedagógica tiene marcas de la sociedad en que está inserta, si bien su especificidad trasciende tales condiciones, pues su cometido es hacer que los estudiantes sean lo más creativos posibles. Pero la creatividad, en todos los campos, no resulta sencillamente de la libertad, sino más bien de un sometimiento consentido: en aras de la satisfacción ligada al producto (la obra artística, el teorema, el desempeño deportivo), se entrena, se practica, se estudia, se hacen esfuerzos durante años... para poder disfrutar de algo que solo tiene lugar como producto de un trabajo duro, sobre unas bases sólidas.

Una fácil especulación política llevó en una época a hablar del "arte comprometido": parecía bastar con la declaración partidaria explícita para ser un escritor. Con ese rasero, malas obras y malos autores se encumbraron (y, en muchos casos, el tiempo se encargó de tumbarlos) y buenas obras y buenos escritores se lanzaron al despeñadero (y, en algunos casos, el tiempo se encargó de reversar la medida). Por esto, muchos artistas - de todas las posiciones políticas - hablan de su compromiso como el de hacer bien su trabajo; y eso no les impide, en cuanto integrantes de una sociedad, intervenir en política, teniendo en cuenta la diferencia entre ambas cosas, así converjan en la misma persona y en el mismo momento. Pongamos por caso a Cortázar (1969, p.125): sabía que el establecimiento trata de comprar 
a los autores "de ideología socialista", y que dependía de ellos el impedirlo o permitirlo; con todo, agregaba que era más difícil tomar distancia de la venta que, de los autores, intentan hacer sus propios copartidarios. Termina diciendo: no te dejes comprar, pibe, pero tampoco vender.

La política aparece en la buena literatura, por supuesto, aunque tratada literariamente. Al escritor Javier Cercas le preguntan por el motivo para hablar de un falso héroe de la Segunda Guerra Mundial. "Quería saber por qué un hombre miente sobre el Holocausto; y, sobre todo: qué hay de ese hombre en todos nosotros" (Semana, 2015, p. 66. Énfasis propio), responde. Esta respuesta explica, a su manera, cómo la literatura trasciende la anécdota, a condición de servirse de ella. Un panfleto no es una obra literaria, así se vista de seda. Y una obra literaria tiene efectos políticos, claro está, mas no por las consignas que enarbole, sino por hurgar - con el arte de la palabra - la herida donde la condición humana es política.

Vemos cómo una posición frente a la dimensión regulativa puede extenderse fatalmente a la dimensión instruccional. En general, se trata de quienes sienten que su labor como educadores es adoctrinar, catequizar (en cualquier color del espectro políticoideológico). En el caso de la enseñanza de la literatura, se trata de trasladar la comprensión del poder al asunto de la especificidad de la literatura. Aunque de banderas distintas, son iguales, en un nivel de análisis, el Index librorum prohibitorum et expurgatorum de la iglesia... y la censura a determinados autores en países con ideología o religión de Estado.

Nada nos impide entender la relativa autonomía entre ambas cosas y trabajar cada una en su especificidad, en su oportunidad, en su contexto; mostrar sus conexiones, sus puntos de encuentro y de desencuentro... y esperar — creadas las condiciones de posibilidad-a que, así como nos ocurrió a nosotros, el otro encuentre en esos dos asuntos un punto de diálogo, de pregunta, quizá una decisión. No obstante, a veces los anti-autoritarios somos autoritarios - $i \sin$ darnos cuenta? - y le imponemos a la literatura, en el marco de su enseñanza, las palabras que quisiéramos escuchar de ella; y les hacemos repetir a los estudiantes los discursos que a nosotros nos gustan... y llamamos a eso, de un lado, "pedagogías críticas" y, del otro, "aprendizaje significativo". En algún caso, ¿se trata de "Buena voluntad mal ilustrada", como dice Bourdieu (1982, p. 36)?

Más allá de sus anécdotas, la literatura no es servil a poder alguno; ni siquiera al que nosotros querríamos ver operando (por justo que sea); ni tampoco a esa ingenuidad de una desaparición del poder ante una mágica igualdad, conquistada por la bondad intrínseca del propósito, sin relación con las condiciones de posibilidad correspondientes.

\section{Lo instruccional, ¿marca lo regulativo?}

Una autoridad auténtica - expresión de Lacadée, en consonancia con Freud (1914) - se produce como efecto del trabajo. Es decir, los estudiantes terminan reconociendo la autoridad del profesor, no es algo ubicado al inicio; hay concesiones previas, claro está, pero solo obtendrán su validación o invalidación de manera retroactiva. Si es así, cuando alguien impone una autoridad autoritaria - otra vez Lacadée- es por no poder producir el efecto de una autoridad auténtica (y no estamos diciendo que solo le competa a él, pues la época está involucrada). En la escuela, la regulación estaría estrechamente ligada a la instrucción: solo se puede intentar regular de manera auténtica, en la medida de la labor llevada a cabo en el ámbito instruccional.

Entonces, cuando hay una falla del lado del saber, una imposibilidad de producir un reconocimiento del otro, se intenta hacer una compensación de dos maneras: (a) Imponer un autoritarismo que, así producido, no se puede eliminar por medio de una prescripción bien intencionada, o (b) renunciar a la regulación, aunque, como hemos dicho, dejar libre ese lugar implica que otra práctica vendrá a ocuparlo.

Para muchos estudiantes, el profesor "bonachón" no enseña pero puede resultar conveniente en el momento (para temas de evaluación, por ejemplo), aunque resulta contraproducente a largo plazo (en relación con la formación). Así, cuando no podemos hacer leer literatura a los estudiantes, entonces quedan dos alternativas, en apariencia:

- Imponerse por la vía autoritaria: amenaza, calificación, apelación a autoridades de mayor nivel. Pero, en tal caso, o bien leen literatura para cumplir (y el efecto formativo no tenderá a producirse), o bien responden en ese mismo nivel, incrementando la indisciplina o, incluso — como se estila hoy - agrediendo al profesor.

- Ubicar la autoridad del lado de los estudiantes; ejemplo: ¿qué quieren leer?, enunciado de buen recibo hoy, cuya enunciación es "no tengo nada que enseñar". Así, se cree obrar de manera "consecuente", al tener en cuenta el nivel de desarrollo, el contexto y el gusto del estudiante. Y, por esa vía - que no es la única一, viene la "literatura de autoayuda", 
para cuyo acceso no se necesita la educación formal. Esta busca transformar el contexto del estudiante, no ajustarse a él. En principio, el mundo literario no pertenece al contexto del estudiante y, por eso, la escuela lo refiere; ella pretende que el estudiante haga contacto con el canon literario a partir de ciertos criterios, lo que difícilmente encontrará por otra vía 6 .

Entonces, en realidad no existen estas alternativas: la única ligada a la autoridad auténtica depende del reconocimiento hecho por el estudiante, a partir del trabajo del maestro, en dirección al saber.

\section{¿Profesar lo instruccional?}

Que la escuela es instruccional salta a la vista cuando se contempla un plan de estudios. El nivel básico se propone enseñar a leer y a escribir, a hacer las operaciones matemáticas, a entender la naturaleza y la sociedad... con el sesgo de una cultura, de una época, claro está, pero no hay manera de evitarlo. Los nombres de las asignaturas hablan de la pretensión instruccional, en relación con saberes acuñados muchas veces hace milenios (como filosofía o álgebra). Además, se presupone que esos saberes no están en la cotidianidad del aprendiz, por lo cual requieren un procedimiento formal (de lo contrario, la escuela sobraría), pues no se accede a ellos por el simple contacto mediático, por el comentario de barriada, o por la opinión familiar.

¿Cómo es en el caso de la literatura? El asunto no deja de ser polémico, pues la literatura no es específicamente un saber a la par de la geometría, la geografía o la geología. La literatura es objeto de saber: historia de la literatura, análisis de los movimientos literarios, descripción de estructuras narrativas. De esos temas, el estudiante no tiene por qué saber; en cambio, se supone que el maestro sí, pues eso dice en el título que presenta para obtener el puesto. Son asuntos con el mismo orden de legitimidad que la física o la sociología... en cuanto saber, no en cuanto literatura. La sujeción de la escuela al saber justificaría tratar ahí a la literatura como objeto de conocimiento. Entiéndase: no estamos hablando de un conocimiento inmutable ${ }^{7}$, sino de una posición frente a cierta prác-

6 Muchas obras están en internet, no así los criterios que se desprenden de una relación con otro (como la que hay entre maestro y estudiante).

7 Con todo, las disciplinas científicas cambian a un ritmo propio, interno, el cual no coincide con las fechas de vencimiento que la actualidad estampa en todo, como condición de su principio según el cual todo está en venta y cuanto más obsolescentes sean los bienes de consumo, mejor (de ahí la obsolescencia programada). tica discursiva. Entonces, es tan desatinado criticar la enseñanza de la literatura que pone en juego un saber (con el argumento de que se mata la literatura en el camino), como criticar la enseñanza de la física diciendo que mata los sueños de volar ( $c f r$. Bourdieu [1982, p. 21]). Ahora bien, el profesor, ¿tiene con ese saber una relación sólida? Cuando no es así, viene el desencanto y entonces creemos falazmente que el problema fue crear un contexto de relación con el estudiante basado en el saber... otra vez el bebé al desagüe, por cuenta del agua sucia.

El saber es una conquista cultural y la escuela pretende, entre otras cosas, estar a su altura, sea la gramática, la mecánica clásica o la tabla periódica. Por supuesto que estamos en sociedades determinadas y, en consecuencia, se cuelan -con iguales pretensiones- la preceptiva literaria, la religión, la cátedra de paz. Ahora bien, no es momento de juzgar el estatuto del saber en cada caso, sino de verificar que la época $-y$, muchas veces, la institución- hace un juicio sobre aquello que es digno de estar en la escuela, en cuanto saber. Asuntos como los movimientos de asignaturas y los cambios de nombre, hablan de la existencia de una pugna permanente sobre los criterios para juzgar tal dignidad... es decir, no niegan que se trate de una decisión en torno al saber. Por eso, al incorporar en ese bando asuntos que son efecto del trabajo, como lo de los valores, por ejemplo (Antelo, 2005), y al pretender tener un control previo de eso, se termina dándoles el estatuto de saberes (asignaturas de ética, religión, o posconflicto), pues, ¿de qué va a hablar un profesor en esos espacios?

En su lección inaugural en el Collège de France, Barthes (1978) habla de la especificidad de la literatura: ella no es un saber, aunque está relacionada con él; igualmente, tiene que ver con cierta "representación" de la realidad, pese a que tampoco es esa su especificidad... usando esos dos terrenos, a su manera, la literatura ejerce su semiosis, su acción sobre el lenguaje mismo, que sería su asunto propio. Entonces, no es del orden del saber y, en cuanto literatura, no sería asunto de la escuela; por eso, la volvemos objeto de conocimiento y, entonces, esa dignidad de la cultura entra a la escuela por la vía del saber. En este punto se sitúa una continua discusión de los maestros del área sobre qué enseñar en la asignatura de literatura: ¿a hacer literatura?, ¿la historia de la literatura?, ¿teoría literaria?, ¿análisis literario? ${ }^{8}$

La polémica, no obstante, oblitera algo esencial: el lugar del saber en la escuela no es todavía la explicación del proceso formativo.

8 Es lo explorado en el primer llamado (Bustamante, 2015). 
Entonces, el maestro profesa un saber. Profesor sería su segunda cara. Y si no lo quiere hacer (o, más triste aún: si no lo hace porque carece de relación con el saber), si se declara más bien un "facilitador" (como escuchamos hoy en día), un panelista del "diálogo de saberes" (porque hasta la idea de "moderador" resulta molesta, aunque se ejerza)... entonces pone algo a cambio. Cuando pone, hemos dicho, aparece - por ejemplo- la "literatura de autoayuda", que elimina prácticamente el sentido de la escuela en el punto en que presenta el canon literario a los nuevos. Sin saberlo, esta dejación del saber es el fin del dispositivo escolar (y tal vez la aparición de otro), pues lo que se enarbola a cambio del antiguo saber - hoy cuestionado por su obsolescencia, tanto como por la de su portador-, son los efectos del trabajo en relación con el saber (los "valores", por ejemplo); pero se entiende que, caído el saber, aquellos efectos no se producirán, y entonces nos quedamos solo con la cantaleta o los buenos -e inútiles- consejos. Y vemos efectivamente que nunca antes se habló tanto de valores como hoy, y sin embargo nunca antes había habido un panorama tan preocupante en ese sentido.

\section{¿Qué es enseñar?}

Además de su relación con un saber, que le granjea un lugar en la escuela, el maestro es alguien que tiene a cargo unos aprendices. Está encargado de profesar un saber, y también está encargado de unas personas (que, en principio - hemos dicho- no quieren saber). Hemos de pensar que tiene dos pasiones: una por el saber y otra por enseñarlo a quien no lo sabe (impares). De haber tenido solo la primera pasión, habría elegido ser un investigador en su campo y hablar ante pares; es el caso del Collège de France, que hemos citado: es una institución donde los catedráticos piensan en voz alta sus investigaciones. Su asunto es producir saber, no enseñarlo. Los asistentes a las conferencias que imparten no son alumnos, no están a cargo de los investigadores. Por eso, la institución no certifica la asistencia, no evalúa, no califica, no expide títulos. Tenemos profesores, pero no enseñantes (que sería la tercera cara del maestro). Los asistentes posiblemente sean algo muy cercano a los pares: personas que entienden de la disciplina en juego y que arriesgan comprender las novedades que, en su marco o contra él, propone el catedrático. Difícilmente se explica de otra manera su asistencia, pues no hay un mecanismo organizado para explicarle al que "no entiende", o para "motivar" al desinteresado. A gusto del investigador, se admiten raras veces inter- venciones del público; $y$, cuando se da el caso, estas no son en el terreno de buscar comprensión, sino de debatir en el marco del rigor del campo.

Esa otra cara del maestro que conduce, hace aparecer otras cosas en la escuela. Lo que llaman "motivación", por ejemplo. Esta supone que el otro no quiere y que la institución ha puesto al maestro - que sabe - para que trate de que el otro quiera, pues, como hemos dicho, de entrada no quiere.

Ahora bien, la tercera cara del maestro - enseñante- está atada a la segunda - profesor, que profesa-. De tal manera, si no se tiene algo para profesar delante del otro, ¿qué se le va a enseñar?, ¿hacia dónde se lo va a conducir? No es que falten lugares, sino que, en ausencia del saber como asunto mismo de la escuela, esos lugares van siendo cada vez más los contenidos de unas idealizaciones irrealizables, el acercamiento entre humanos por sí mismo (lo cual lo expone a las vicisitudes del lazo humano, que no son las más deseables), los estereotipos de la política social que no forma a los estudiantes... y los efectos formativos se producen, no dan espera; pero, entonces, ¿qué efectos formativos produce un espacio que destaca cada vez más la asistencia social, que se ufana de aislar por un rato a los jóvenes de los problemas de la sociedad, que repite para las paredes la monserga de la política educativa, que no ofrece alternativas a lo que los mismos jóvenes van construyendo en su lógica de separación del adulto?

Parece una buena pregunta de investigación, ¿cierto?

\section{Referencias bibliográficas}

Antelo, E. (2005). Notas sobre la (incalculable) experiencia de educar. En Educar: ese acto político. Buenos Aires: Del Estante Editorial.

Bachelard, G. (1978 [1949]). El racionalismo aplicado. Buenos Aires: Paidós.

Barthes, R. (1978). Leçon. Paris: Du Seuil.

Bernstein, B. (1999 [1993]). La estructura del discurso pedagógico. Madrid: Morata-Paideia.

Bourdieu, P. (2002 [1982]). Lección sobre la lección. Barcelona: Anagrama.

Bourdieu, P. (2003 [2000]). El oficio de científico. Ciencia de la ciencia y reflexividad. Barcelona: Anagrama.

Bustamante, G. (2013). Sujeto, sentido y formación. Bogotá: San Pablo-Universidad Pedagógica Nacional. 
Bustamante, G. (2015). Algunas vicisitudes de la enseñanza de la literatura. En Enseñanza de la literatura: perspectivas contemporáneas. Serie Eventos, 3. Bogotá: Universidad Distrital Francisco José de Caldas.

Cortázar, J. (2010 [1969]). No te dejes. En Último round [piso de abajo]. México/Barcelona: RM.

Freud, S. (1990 [1910]). Contribuciones para un debate sobre el suicidio. En Obras completas. Vol. XI. Buenos Aires: Amorrortu.

Freud, S. (1990 [1914]). Sobre la psicología del colegial. En Obras completas. Vol. XIII. Buenos Aires: Amorrortu.

Freud, S. (1990 [1932]). Conferencia 34. En Nuevas conferencias de introducción al psicoanálisis. En Obras completas. XXII. Buenos Aires: Amorrortu.

Kant, I. (2003 [1803]). Pedagogía. Madrid: Akal.

Lévi-Strauss, C. (1983 [1960]). El campo de la antropología. En Antropología estructural. México: Siglo Xxi Editores.

Lacadée, P. (2015). Conferencia en la Universidad Nacional de Colombia, durante la III Semana del Autismo en Bogotá. 5 de agosto de 2015. Disponible en http://infanciayjuventud.co/iii-semana-del-autismo-en-bogota-2/
Marx, C. (2005 [1859]). Contribución a la crítica de la economía política. México: Siglo XxI Editores.

Ministerio de Educación Nacional. (1994). Lineamientos generales de procesos curriculares. Hacia la construcción de comunidades educativas autónomas. Bogotá: Autor.

Ministerio de Educación Nacional. (2006). Estándares básicos de competencias del lenguaje. En Estándares básicos de competencias en lenguaje, matemáticas, ciencias y ciudadanas. Bogotá: Autor.

Nussbaum, M. (1995 [1991]). La imaginación literaria en la vida pública. En Isegoría 11. Disponible en http:// isegoria.revistas.csic.es/index.php/isegoria/article/ view/254/254

Platón. [2011] Teeteto o de la ciencia. En Diálogos II. Madrid: Gredos.

“'Quien no corre riesgos, que no escriba': Javier Cercas”. (2015, 18 de enero). Semana, 1707, 66.

Quignard, P. (2012 [1996]). El odio a la música. Buenos Aires: El Cuenco de Plata.

Weber, Max (2009 [1904]). La "objetividad" del conocimiento en la ciencia social y en la política social. Madrid: Alianza. 


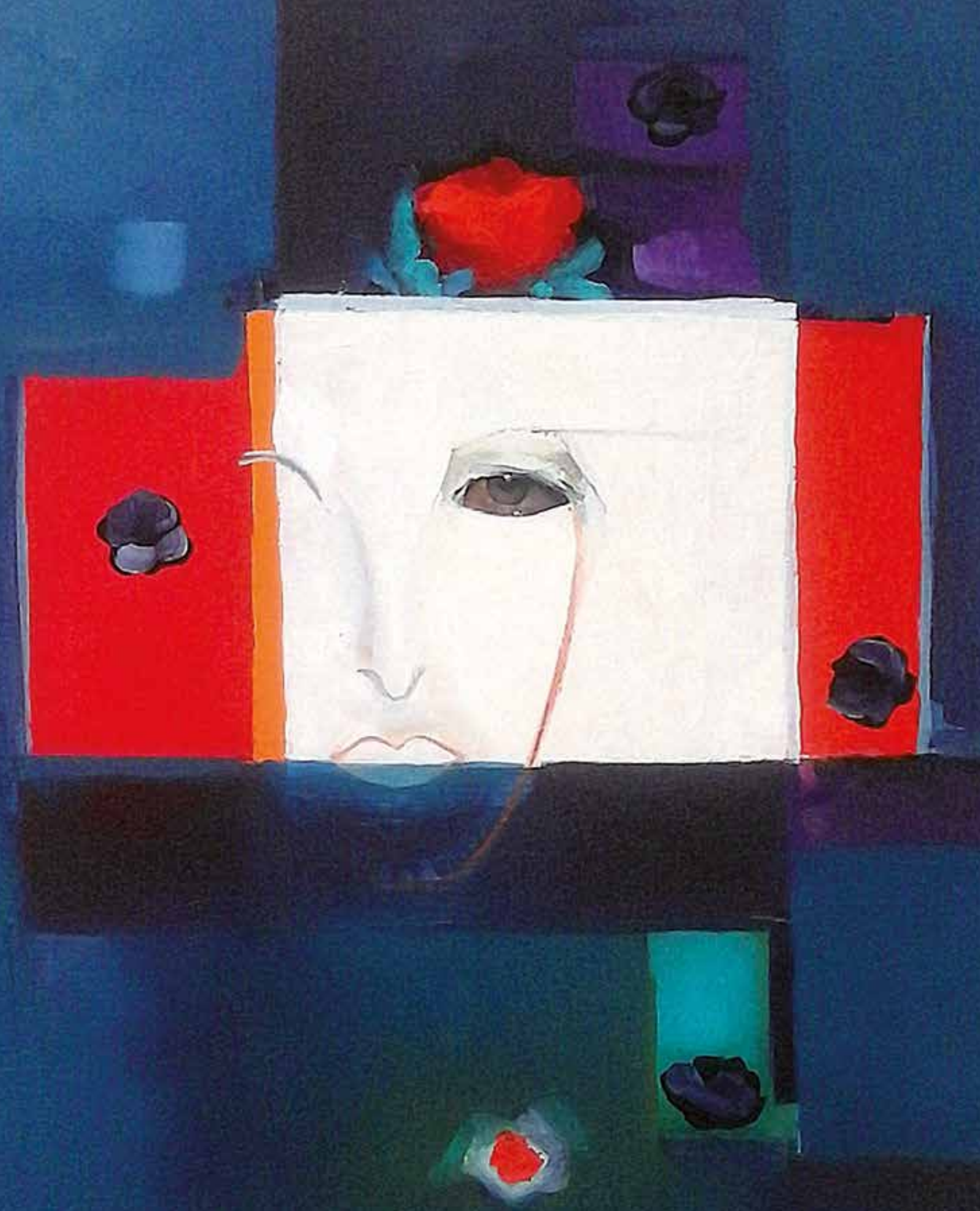

Título: Ventana Autor: Guillermo Quintero Valderrama Técnica: Óleo sobre tela Dimensiones: $50 \times 40 \mathrm{~cm}$ 